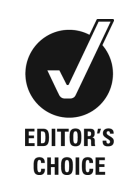
Medicine, Naval Health Clinic Hawaii, JBPHH, Honolulu, Hawaii, USA

${ }^{2}$ Department of Pathology, Tripler Army Medical Center, Honolulu, Hawaii, USA

${ }^{3}$ Department of Dermatology, Tripler Army Medical Center, Honolulu, Hawaii, USA

\section{Correspondence to} Dr Cody Ronald Jackson, sponsorw@gmail.com

Accepted 10 January 2015

CrossMark

To cite: Jackson $C R$, Fernelius C, Arora N. BMJ Case Rep Published online: [please include Day Month Year] doi:10.1136/bcr-2014207139

\title{
Ramifications of poor medical education and screening in minority populations: an extensive acral melanoma
}

\author{
Cody Ronald Jackson, ${ }^{1}$ Colby Fernelius, ${ }^{2}$ Navin Arora ${ }^{3}$
}

\begin{abstract}
SUMMARY
After 2 years of holistic self-treatment on his home island, an elderly Samoan man presented with a painful, hyperpigmented mass on his left heel. Physical examination revealed a black, friable tumour with necrotic tissue and superficial ulcerations with no other associated symptoms. Further investigation revealed that the mass was invasive. The tumour was treated with resection and a final diagnosis of acral lentiginous melanoma, stage T4b was made. Poor access to care and screening services are large barriers to care for minorities and patients with low socioeconomic status. Once access is obtained, however, patient compliance is not guaranteed. Healthcare practices often clash with societal beliefs, and so patient education regarding their disease and its possible progression, along with treatment options, is important. Furthermore, a lack of ethnically diverse physicians contributes to low cultural competency during interaction with patients from minorities, resulting in poor communication and low patient satisfaction.
\end{abstract}

\section{CASE PRESENTATION}

An 82-year-old Samoan man, skin phototype V, presented with left heel pain due to a large, exophytic, hyperpigmented, polypoid mass. He had initially presented to the dermatology clinic 2 years previously with a small, dark macule, but had decided to self-medicate holistically on his home island until his heel pain prompted his return. Physical examination revealed a lesion consisting of black, necrotic nodules and friable granulation tissue along with ulcerations and purulent/serosanguinous discharge. At the base of the lesion was a hyperpigmented, asymmetrical macule with nodularity (figure 1). The patient had no other associated symptoms and no lymphadenopathy.

An MRI demonstrated a $9 \times 7 \mathrm{~cm}$ lobulated, exophytic left heel soft tissue mass with invasion into the fat pad, but no other tissue invasion or bone erosion. Biopsies from the medial and plantar surfaces of the macular lesion showed marked pigment deposition throughout all levels of the epidermis and in the superficial dermis (figure 2). The histopathological findings also revealed lentiginous proliferation of atypical melanocytes associated with irregular epidermal acanthosis along with prominent pagetoid spread of atypical intraepidermal melanocytes (figure 3). Atypical melanocytes were noted at dermal papillae tips, but it was difficult to discern any definitive invasion into the dermis.

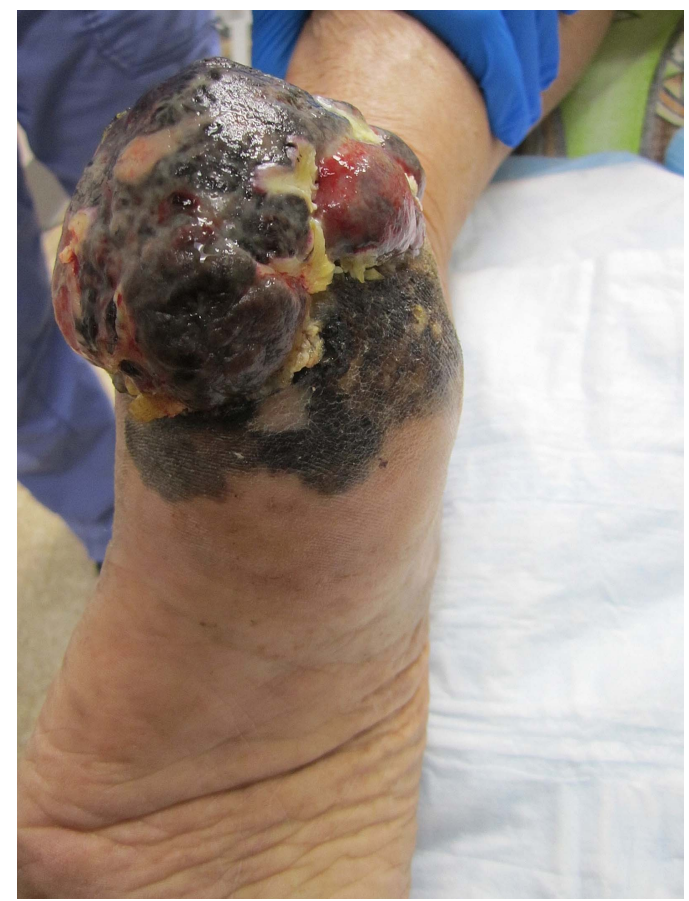

Figure 1 Large, exophytic, hyperpigmented, polypoid, acral mass.

These initial findings suggested a diagnosis of acral lentiginous malignant melanoma in situ with a vertical growth phase resulting in an extensive nodule. Although definitive features of invasive melanoma were not identified, given the patient's history, the small sample size of tissue, and the lack of biopsies from the fungating mass, it was felt that tumour excision was the most appropriate treatment.

A sentinel node biopsy was negative so a belowthe-knee amputation was carried out. Gross examination of the prosection revealed clear margins and findings of a variably pigmented (white to black) lesion with a focal area of fungating tumour measuring about $9 \times 7 \times 3 \mathrm{~cm}$. Adjacent to this fungating mass, covering approximately half of the lateral aspect of the foot, was an ill-defined, grey-blue discolouration measuring $11 \times 8 \mathrm{~cm}$. Finally, located $0.4 \mathrm{~cm}$ medially from the variably pigmented lesion and grossly separate from the main lesion, was a well-demarcated, slightly firm, black lesion measuring $0.5 \times 0.5 \times 0.2 \mathrm{~cm}$. Microscopic findings of the fungating mass revealed superficial ulceration and an underlying multinodular, heavily pigmented mass with gross extension into the adjacent adipose 


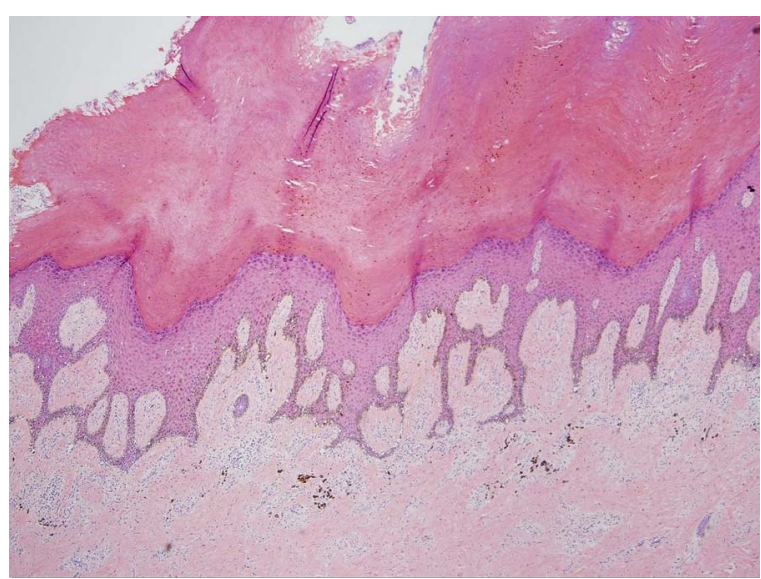

Figure 2 Marked pigment deposition throughout the basal layer $(\mathrm{H} \& \mathrm{E}, \times 4)$.

tissue that measured $3.2 \mathrm{~cm}$ Breslow depth. Additional histopathological findings of the mass and lesions were consistent with biopsy results and also demonstrated invasion into the dermis and subcutaneous tissues. Midway through the dermis, prominent regression was indicated by tumoural melanosis and fibrosis. Deeper to this, the tumour extended into the subcutaneous tissue without pigmentation, which was supported by findings of marked cytological atypia that included pleomorphism, abnormal chromatin patterns and atypical mitotic figures (figure 4). The mitotic count was $15 / \mathrm{mm}^{2}$ with the hot spot method. No definitive lymphovascular invasion or perineural invasion was identified. Acral lentiginous melanoma, stage T4b was the final diagnosis (figure 5).

\section{GLOBAL HEALTH PROBLEM LIST}

- Minorities with darker skin tones are at higher risk for acral melanomas.

- Minorities and those with low socioeconomic status (SES) usually present with advanced disease.

- Minorities and those with low SES have decreased access to healthcare due to various barriers.

- Populations with low SES have poor access to secondary preventive medicine.

- Poor diversity among healthcare providers results in decreased cultural competency.

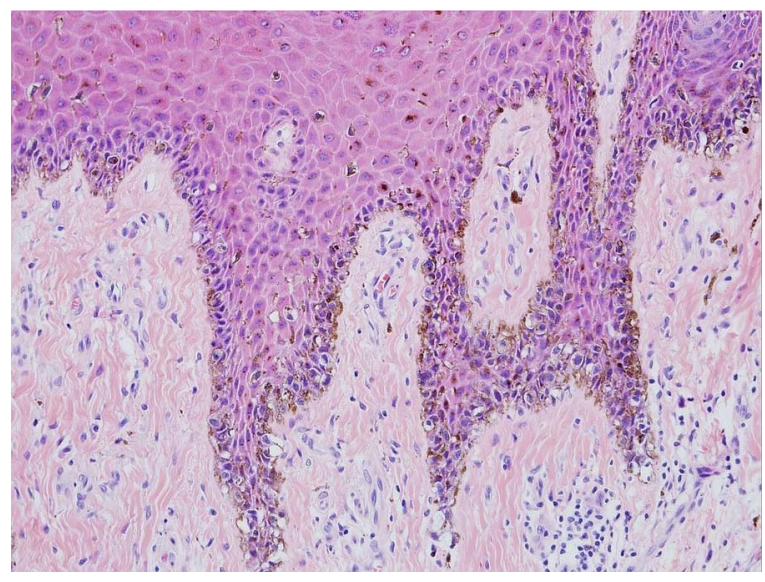

Figure 3 Lentiginous proliferation of atypical melanocytes in the basal layer of the epidermis, with some scattered pagetoid spread $(H \& E, \times 20)$.

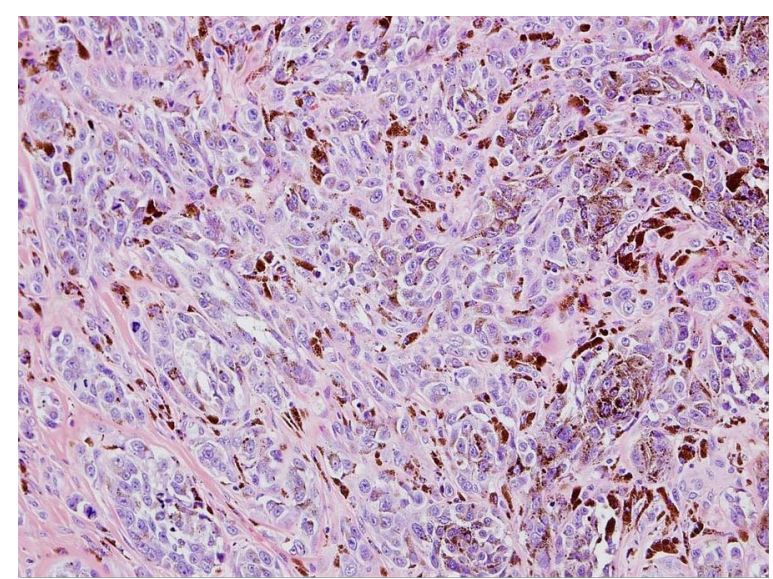

Figure 4 Large, pigmented, pleomorphic cells with nucleoli and chromatin irregularities. Multiple mitotic figures, some atypical, are present $(H \& E, \times 20)$.

\section{GLOBAL HEALTH PROBLEM ANALYSIS}

According to a report from California, Native Hawaiians and Pacific Islanders (NHPI) were one of only two racial groups where the leading cause of death was cancer, with rates above the national average. ${ }^{1}$ Acral lentiginous melanomas are the most common form of melanoma (29-72\%) in dark-skinned individuals, with a median age of onset of 65 , and often result in a higher mortality rate due to misdiagnoses in favour of more common diseases. ${ }^{2}$ Minorities with darker skin tones have a higher risk of acral melanoma. ${ }^{3}$ Additionally, minorities and those with low SES usually present with thicker lesions and more advanced disease, leading to a higher mortality rate. ${ }^{3-5}$

Worse health outcomes in low SES populations are likely due to poor secondary prevention, such as low access to skin screening services and lack of patient education on harmful melanocytic lesions. ${ }^{3} 4$ One study found that women and younger patients tend to seek medical screening services more often than men and older individuals. ${ }^{6}$ Another study revealed that low SES patients generally know little about their own medical condition, tend to have a high school education or less, and have difficulties arranging transport, all factors contributing to care barriers. $^{7}$ Meanwhile, those with a higher SES are generally better educated with more medical knowledge, and are aware that skin changes can indicate cancer. ${ }^{5}$ Therefore, patients with higher SES tend to recognise skin changes when they self-screen and obtain medical treatment earlier than lower SES patients. ${ }^{5}$

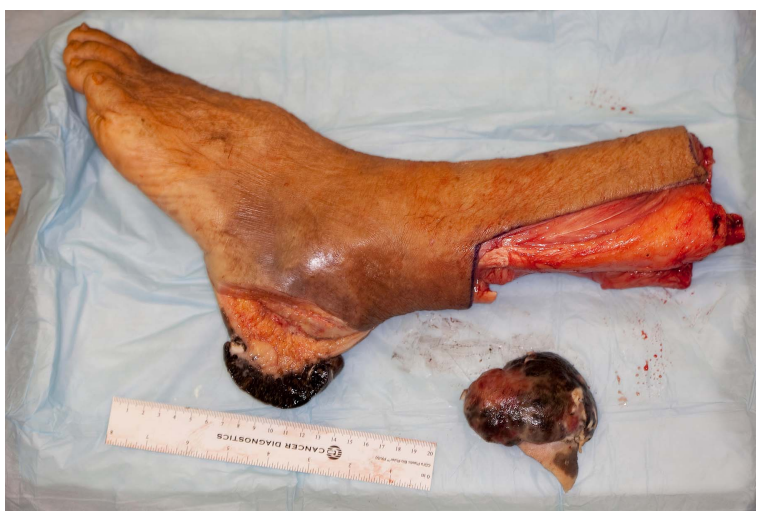

Figure 5 Amputated affected limb and dissection of the acral mass. 
Our case concerning an elderly man from a remote Pacific island, supports this notion of barriers to care and delayed seeking of care due to lack of understanding and knowledge of disease and the long distances that must be travelled to obtain proper, specialty care. Rural and isolated populations share similar characteristics regarding access to care. Several studies have shown that poor access to care for these populations is mainly due to remoteness, travel time, lack of specialty care, and the cost of obtaining healthcare services, with longer distances correlating with infrequent doctor visits, decreased use of preventive services and fewer routine follow-up visits. ${ }^{8-10}$

Multiple studies have shown that having a usual source of care (person or place where one receives healthcare) improves access to medical screening services and decreases health disparities; however, this is often not available to minorities. ${ }^{7}$ 11-13 Language proficiency, insurance availability, time away from work, and low income combined with out-of-pocket expenses, and even lack of citizenship, are some of the barriers experienced by minorities that prevent them from having a usual source of care, thus leading to health disparities and poorer overall health. ${ }^{1} 1415$

Insurance availability is likely the main barrier. Having health insurance decreases health disparities among high and low SES groups by facilitating access to preventive and primary care while lowering the overall cost. ${ }^{13} 1516$ Although many uninsured minorities are eligible for insurance, they often do not sign up for it due to lack of awareness or limited proficiency in English, ${ }^{11}$ although a Californian study showed high $(88 \%)$ English proficiency among NHPI. ${ }^{1}$

Another barrier to care is lack of cultural understanding or competency by the physician. Generally, physicians withhold more clinical information from minority patients, who then often feel excluded from medical decision-making concerning their own care. ${ }^{11}$ Typically, the ethnicity of physicians does not reflect that of their patients, ${ }^{1}$ who consequently believe that their physician is unaware of popular cultural alternative/holistic medicine. ${ }^{11}$ Perhaps a Samoan provider would have related better to our patient at an earlier point of care and, although understanding his wish to try homeopathic treatment, would have educated him about his advanced disease and need for modern medical treatment, thus leading to a better outcome.

Differences in cultural background and language difficulties can cause a breakdown in physician-patient communication, leading to decreased trust in the physician and poor quality of care due to lack of patient compliance, which results in fewer primary care visits and decreased use of preventive services. ${ }^{11}$ A diverse and/or engaged healthcare team can build greater cultural competence and provide high-quality care to all patients as there is clearer communication and better patient understanding of their condition and treatment options, which creates trust and increases patient satisfaction. ${ }^{11}$

\section{Patient's perspective}

The patient's family declined to provide a written statement.

\section{Learning points}

- Acral melanoma rates are increased in minority populations.

- Tumour thickness is the most important prognostic factor in localised melanoma.

- Patient education, access to care, and early intervention are primary tools for detecting early melanoma, thus preventing advanced disease and decreasing mortality.

- A usual source of care, often provided by insurance companies, enhances preventive and screening services, but may be less used by minorities due to language barriers and work constraints.

- Healthcare providers' increased cultural competency leads to improved health outcomes in minority patients and higher patient satisfaction.

Contributors The patient initially presented to NA, who recognised the importance for this case report and developed the concept. CRJ performed the literature review and was the main writer. CF captured the images.

Competing interests None.

Patient consent Obtained.

Provenance and peer review Not commissioned; externally peer reviewed.

\section{REFERENCES}

1 Ponce N, Tseng W, Ong P, et al. California Asian Pacific Islander Joint Legislative Caucus. The State of Asian American, Native Hawaiian and Pacific Islander Health in California Report. California: California Program on Access to Care, California Program on Opportunity and Equity, and Kaiser Permanente, 2009.

2 Bailey EC, Sober AJ, Tsao H, et al. Chapter 124. Cutaneous Melanoma. In: Goldsmith LA, Katz SI, Gilchrest BA, et al. eds. Fitzpatrick's Dermatology in General Medicine, 8e. New York, NY: McGraw-Hill; 2012. http://accessmedicine.mhmedical. com.Irc1.usuhs.edu/content. aspx?bookid=392\&Sectionid=41138842. Accessed November 10, 2014

3 Ortiz CA, Goodwin JS, Freeman JL. The effect of socioeconomic factors on incidence, stage at diagnosis and survival of cutaneous melanoma. Med Sci Monit 2005; 11:RA163-72.

4 Linos E, Swetter SM, Cockburn MG, et al. Increasing burden of melanoma in the United States. J Invest Dermatol 2009;129:1666-74.

5 Idorn LW, Wulf HC. Socioeconomic status and cutaneous malignant melanoma in Northern Europe. Br J Dermatol 2014;170:787-93.

6 Reyes-Ortiz CA, Goodwin JS, Freeman JL, et al. Socioeconomic status and survival in older patients with melanoma. J Am Geriatr Soc 2006;54:1758-64.

7 Starfield B, Shi L. The medical home, access to care, and insurance: a review of evidence. Pediatrics 2004;113:1493-8.

8 Nemet GF, Bailey AJ. Distance and health care utilization among the rural elderly. Soc Sci Med 2000;50:1197-208.

9 Person DA. Pacific Island Health Care Project: early experiences with a web-based consultation and referral network. Pac Health Dialog 2000;7:29-35.

10 Smith ML, Dickerson JB, Wendel ML, et al. The utility of rural and underserved designations in geospatial assessments of distance traveled to healthcare services: implications for public health research and practice. J Environ Pub Health 2013;2013:960157.

11 American College of Physicians. Racial and ethnic disparities in health care, updated 2010. Philadelphia: American College of Physicians, 2010. Policy Paper.

12 Ettner SL. The timing of preventive services for women and children: the effect of having a usual source of care. Am J Pub Health 1996;86:1748-54.

13 James C, Thomas M, Lillie-Blanton M, et al. eds. Key Facts: Race, Ethnicity, and Medical Care. The Henry J. Kaiser Family Foundation. Report number: 6069-02, 2007.

14 Alexander GC, Casalino LP, Meltzer DO. Patient-physician communication about out-of-pocket costs. JAMA 2003;290:953-8.

15 Blendon RJ, Buhr T, Cassidy EF, et al. Disparities in physician care: experiences and perceptions of a multi-ethnic America. Health Aff (Millwood) 2008;27:507-17.

16 Institute of Medicine. Coverage matters: insurance and health care. Washington: National Academies Press, 2001. 


\section{Global health}

Copyright 2015 BMJ Publishing Group. All rights reserved. For permission to reuse any of this content visit http://group.bmj.com/group/rights-licensing/permissions.

BMJ Case Report Fellows may re-use this article for personal use and teaching without any further permission.

Become a Fellow of BMJ Case Reports today and you can:

- Submit as many cases as you like

- Enjoy fast sympathetic peer review and rapid publication of accepted articles

- Access all the published articles

- Re-use any of the published material for personal use and teaching without further permission

For information on Institutional Fellowships contact consortiasales@bmjgroup.com

Visit casereports.bmj.com for more articles like this and to become a Fellow 